\title{
CLOUD PLATFORM FOR WASTE MANAGEMENT INDUSTRY IN RUSSIA
}

\author{
Vyacheslav Chernikov \\ Voronezh State Technical University, Voronezh, Russia
}

\begin{abstract}
During the last 5 years Waste Management became one the most important topics in Russian society. There are a lot of initiatives related to recycling economy but only few of them are trying to describe waste management as a whole scalable system process. This article describes a cloud platform 'Ya razdelyayu' ('I separate', in Russian) based on main aspects of waste management industry: high-level support of multi-role business process, education and motivation of all participants (citizens, businesses and government), providing communication channels for all players. Currently project status is an early development stage. This article contains a high-level description of cloud platform "Ya razdelyayu".
\end{abstract}

\section{KEYWORDS}

Waste Management, Cloud Platform, Mobile Applications, Architecture, Azure

\section{INTRODUCTION}

In 2015 author became part of the research project to find ways to modernize of Waste Management Industry in Russia. Project was started with analyzing the current state of the waste management in Voronezh city (Russia) as an 'average Russian city'. More than 20 leading local experts and business players were interviewed. It helped to get a vision of the problem.

As a second step system dynamics approach was applied to determine the vision with 'cause and effect' manner. It helped Elena Bakhanova (on the team members) to formalize (Repnoe School, 2019) the relationships between different aspects of functioning waste management in Voronezh region. Scaled down version of created 'cause and effect' model shown on Figure 1.

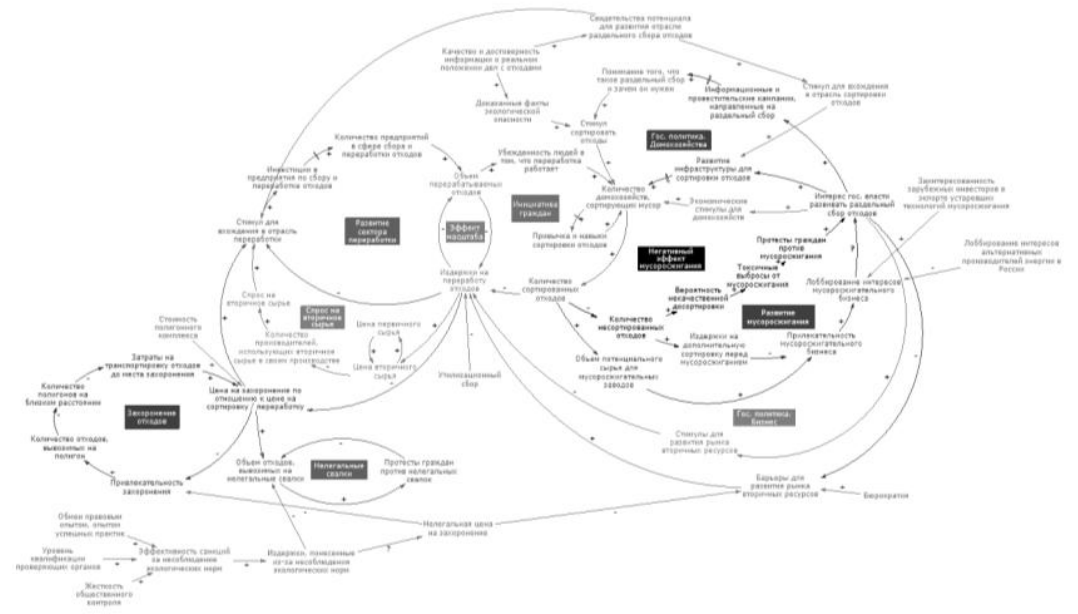

Figure 1. System 'cause and effect' model of waste management process

Details of 'cause and effect' model is described in (Repnoe School, 2016) and not used to the current article. Than project team recognized that this model is not enough to explain ways of creating a Waste Management Industry in Russia. 
To make a process of waste management in recyclable way team focused on economic aspects and multi-role business process. This approach helped team to formalize the process using Business Analysis (International Institute of Business Analysis, 2015). The final scheme of formalized business process shown on Figure 2.

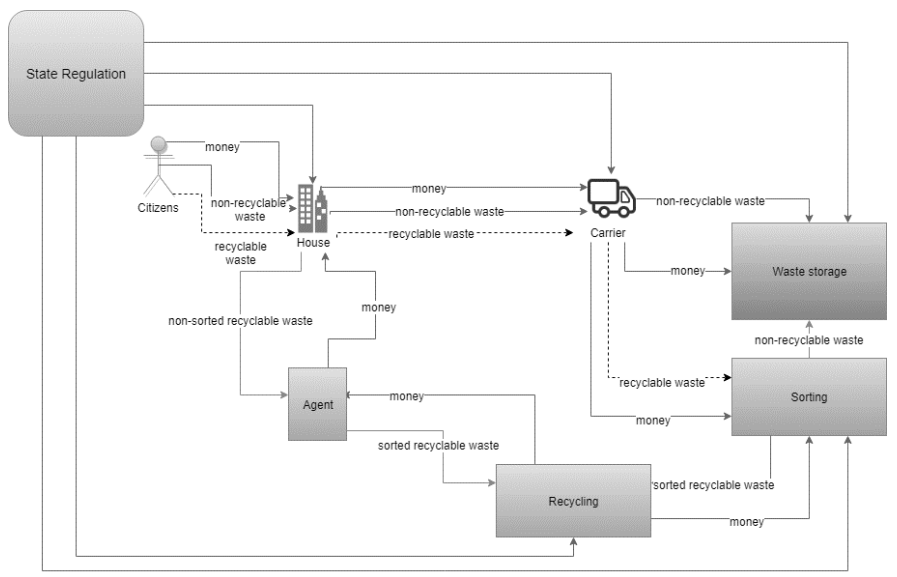

Figure 2. High-level business process of waste management with recycling

This business process model was used by Dmitry Kavtaradze (mentor of project) to create an imitation game that was split in two parts: with waste segregation and without segregation. Game was played with 30 university students and showed that citizens are ready for waste segregation in the case they will get a feedback by the system. This feedback can be provided as a payback (preferable) for recyclable waste or as 'trust signs' (e.g. information that 'my waste was really recycled'). 'Black box' schemes without any feedback demotivated players and they stopped segregation within a short period of time.

To find the way of improving the Waste Management Industry with sustainable recycling process, project team described all business roles involved into waste management:

- $\quad$ State regulators.

- Carriers.

- Citizens.

- $\quad$ Sorting business.

- $\quad$ Recycling business.

- Waste store warehouse.

All these roles have its own behavior patterns and regulative rules described in (Repnoe School, 2019). To support activities by all business process roles and make it sustainable Cloud Platform is necessary. Below chapters contain the high-level vision (by article author) of Cloud Platform to form a sustainable Waste Management Industry with waste segregation.

\section{CLOUD PLATFORM FOR WASTE MANAGEMENT INDUSTRY}

In order to find a way to make an IT solution for managing the whole process (from citizens to products based recycled materials) other approaches (including (Kumar, Sunil et al, 2017), (Poon, Chi S., 1997), (Aazam, M. et al, 2016), (Sharmin, S. et al, 2016)) were analyzed. Approach described in this paper is focused on making a complex chain from kitchen (citizens habits) to final products with recyclable materials. Our final vision of IT complex is:

- mobile and web apps for citizens with information, motivation and getting feedbacks/requests/complains;

- mobile and web apps for state service workers to handle requests/complains/accidents and get reports with key KPI's and information for business players;

- mobile, web and IoT apps for business players to collect tracks of trash vehicles, key numbers and transactions, track planning, information about other business players and interface to communicate with state services and citizens 
- cloud platform to handle and store all the data, analyze requests and complains with artificial intelligence, process with blockchain all transactions and requests/complains, process user activities, provide backend for user information, analyze collected data to find ways of increase the overall level of recycled waste.

The main goal of developing a unified cloud platform "Ya razdelyayu" is the integration of all market players in the solid waste recycle within the region or country. Key areas for which the cloud platform will be created:

- $\quad$ organization, regulation and optimization of solid waste recycling business process across a region or country;

- $\quad$ involvement of the citizens and business in the process of recycling the solid waste;

- $\quad$ provide direct communication channels for all market players with rating-based feedbacks.

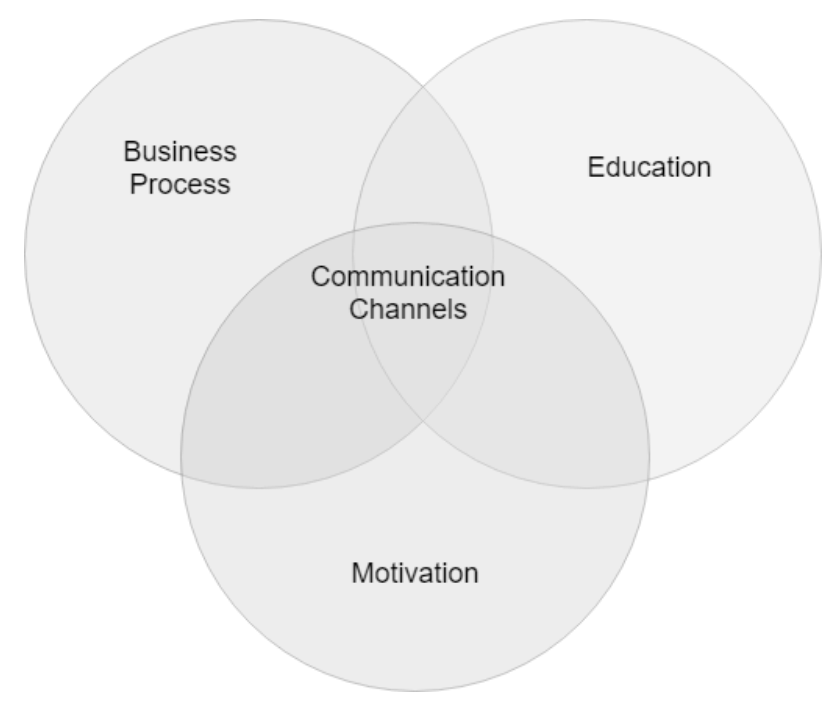

Figure 3. Units of Cloud Platform for Waste Management Industry

The diagram on Figure 3 shows the key functional blocks of the cloud platform. They are divided into the following domains:

- $\quad$ Business Process (help businesses to do the job in effective way);

- $\quad$ Education (provide educational materials for citizens, business and state services);

- Motivation (provide ratings, feedbacks, statuses, money support of market players, citizens and state services).

To integrate all these blocks into a solid system communication channels should exist. There are two main types of communication messages:

1. Messages with requests, complains, feedbacks, ratings by all business process players. Should be based on smart-contracts technology to track the statuses and contract completion. Also will be pre-processed with artificial intelligence services to reduce the level of "fake", "incomplete" and "junk" messages and although provide automatic responses with possible answers.

2. Transactions of money and waste between all business process players (citizens, business, state) based on blockchain technology.

The key concept of cloud platform "Ya razdelyayu" is to provide most valuable features for end users. That's why the Agile approach (Rothman, J., 2016) should be used on behalf of DevOps practices.

\section{HIGH-LEVEL ARCHITECTURE OF CLOUD PLATFORM}

Cloud Platform itself should consist of many parts. On the Figure 4 you can see the high-level solution architecture of the Platform. 


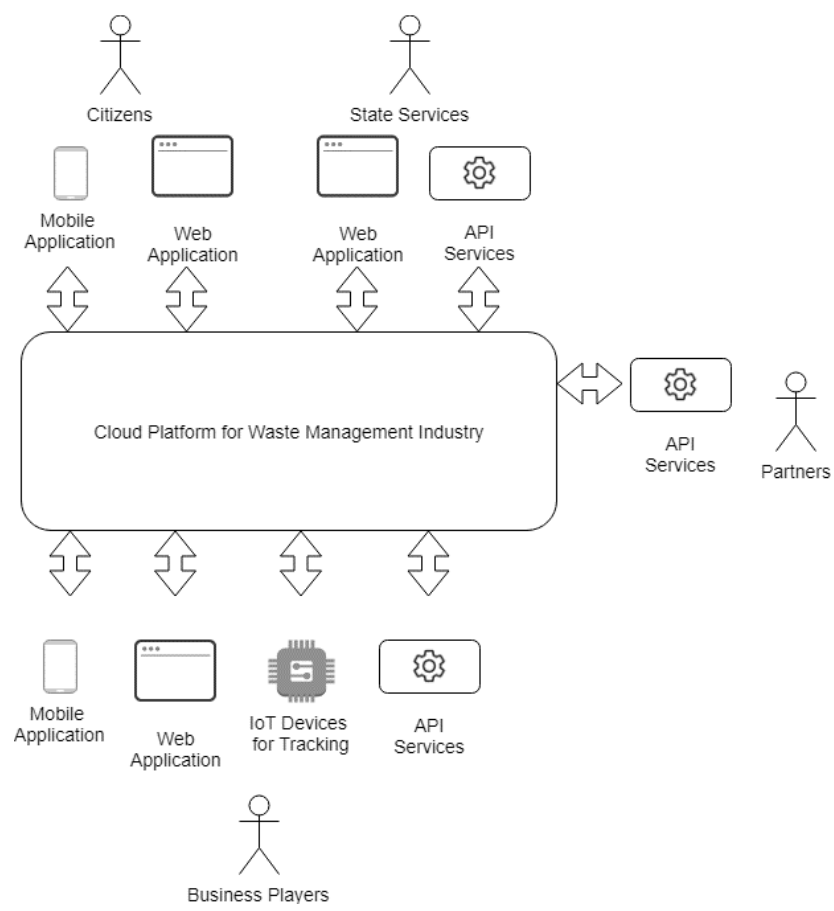

Figure 4. High-level architecture of Cloud Platform for Waste Management Industry

Cloud Platform itself is a set of services for providing different application interfaces (API), collecting and storing data, monitoring of key values and implementing different communication channels. The set of user applications (interfaces) should be developed:

- for citizens: Mobile and Web applications to get a learning material, providing feedbacks, involving into Rating System;

- $\quad$ for state services: Mobile and Web application for getting statistics and education of all players, API services for integration with other online services;

- for business players: Mobile application for on-site jobs workers, Web application for backoffice tasks, IoT devices for tracking key values, API services for integration with on-premise systems;

- for partners: providing API services for retrieving of statistics.

To simplify and speed up the development of Mobile and Web application it's possible to use the Rapid Software Design approach introduced in (Chernikov, V., 2018), (Chernikov, V. et al, 2018).

The detailed vision of the architecture should be specified during the pilot projects described in (Repnoe School, 2019).

\section{CURRENT PROJECT STAGE AND FUTURE WORKS}

Currently project is in MVP (Minimum Viable Product) stage of development the major functionality to find base values for active citizens, state service and business partners. During the MVP stage the following applications will be developed:

1. Mobile applications (iOS/Android) for active citizens:

- maps with points accepting sorted recyclable waste (glass, paper, batteries, plastic, etc.) and contact information;

- show the whole waste management process - current with harm of environment and new with recycling; provide basic education material of separate collection in 2 fractions (dry recyclable and organic/wet non-recyclable);

- send requests to join the separate waste collection program (install containers near to activist's house); monitoring a number of such requests to see leaders (largest number of requests from one area); also, activists should be able request an on-site training for neighbors; 
- send request to sell collected sorted materials (plastic, paper, glass, etc.); partnered business workers will arrive to the destination address and buy collected materials; every request will contain a photo of materials as a proof of necessary minimum amount; all recycled materials weight/volume will be tracked by buyer and activist (who sell) will see how much of waste was recycled;

- send feedback about application and service (with photo);

- get news and updates from service.

2. Mobile applications (iOS/Android) for partnered waste resellers to handle requests.

3. Web application for content and user management, handle requests and feedbacks from users.

4. Backend service that will provide a set of APIs for mobile applications.

5. Database for collecting all the data.

6. Storage service for photos.

MVP version will be implemented using Microsoft Azure Cloud Service, ASP.Net and Xamarin frameworks for developing applications (mobile, web, backend). Also, such services like Azure SQL Database, Azure Storage (BLOB, Queue), Azure Notification Hub will be used. Azure DevOps and Visual Studio App Center services will be used to implement Continues Integration and Continues Delivery processes.

As a first step to attract users these applications will be introduced to Russian ecological communities and local waste resellers. It will help to integrate separate waste collection in areas with high number of activists.

Following steps will include additional options for households and sorting businesses.

\section{CONCLUSION}

This article contains a high-level vision of Cloud Platform that should be used for modernizing Waste Management Industry in Russia. This vision was created as a result of 3 years research project hosted by Repnoe School (Voronezh, Russia, http://repnoe.net).

To implement a sustainable business process of Waste Management it's necessary to add Education and Motivation domains into Cloud Platform and implement the whole system in parallel with offline activities.

Cloud platform should provide a different interface for different types of users and focused on key number - ratio between recycled/not recycled solid waste.

\section{REFERENCES}

Aazam, M. et al, 2016. Cloud-based smart waste management for smart cities. IEEE 21st International Workshop on Computer Aided Modelling and Design of Communication Links and Networks (CAMAD), Toronto, Canada, pp. 188-193.

Chernikov, V. et al, 2018. Methodology of Developing Cross-platform User Applications. Bulletin of Voronezh state technical university, Vol. 5, No. 14, pp. 18-25.

Chernikov, V., 2018. Approach to Rapid Software Design of Mobile Applications' User Interface. Proceedings of the 23rd Conference of Open Innovations Association FRUCT, ser. FRUCT'23, Bologna, Italy, pp. 105-111.

International Institute of Business Analysis, 2015. BABOK: v3: a guide to the business analysis body of knowledge. International Institute of Business Analysis. Toronto, Canada.

Kumar, Sunil et al, 2017. Challenges and opportunities associated with waste management in India. The Royal Society, Vol. 4, No. 3, doi:10.1098/rsos.160764

Poon, Chi S., 1997. Management and Recycling of Demolition Waste In Hong Kong. Waste Management \& Research, Vol. 6, No. 15, pp. 561-572.

Repnoe School, 2016. Waste management system in Voronezh City [accessed 2016 Apr 8] http://www.repnoe.net/docs/musor/Repnoe-TKO-Aprel-2016.pdf

Repnoe School, Forthcoming 2019. The Way to Waste Management Industry in Russia. Repnoe School Publishing. Voronezh, Russia.

Rothman, J., 2016. Agile and lean program management: scaling collaboration across the organization. Practical Ink. Victoria, Canada.

Sharmin, S. et al, 2016. A Cloud-based Dynamic Waste Management System for Smart Cities. Proceedings of the 7th Annual Symposium on Computing for Development, ACM, p. 20. 